\title{
INTERVENÇÕES ANTRÓPICAS EM UMA BACIA HIDROGRÁFICA E CONFLITOS PELO USO DA ÁGUA: O CASO DA LAGOA FEIA
}

\author{
R. R. JESUS ${ }^{1}$, V.P. S.OLIVEIRA, M. M.OLIVEIRA \\ Instituto Federal Fluminense \\ engenheiroronald@gmail.com ${ }^{1}$
}

Artigo submetido em 25/10/2018 e aceito em 24/06/2019

DOI: $10.15628 /$ holos.2019.7876

\begin{abstract}
RESUMO
Desde o início da ocupação territorial da bacia hidrográfica da lagoa Feia, foram promovidas alterações na dinâmica hídrica, a qual era considerada empecilho ao desenvolvimento. O cultivo de cana-de-açúcar foi destaque na região, uma vez que as condições naturais locais eram favoráveis à cultura. A expansão da atividade demandou a implementação de diversas obras de drenagem de áreas alagadas, redução das lagoas e calhas de rios. Neste sentido, neste trabalho objetivou-se elaborar uma revisão bibliográfica identificando as principais intervenções antrópicas no regime hídrico da bacia hidrográfica da lagoa Feia, correlacionando-as com conflitos pelo uso da água. Para tal, foram feitas pesquisas em meios impressos e digitais, incluindo
\end{abstract}

pesquisas em plataformas de buscas como o Portal de Periódicos CAPES/MEC e o Google Acadêmico. A análise dos estudos permitiu concluir que a forma como se deu a ocupação da bacia hidrográfica da lagoa Feia, justificada pela constante necessidade de ampliação das áreas agricultáveis e de pastagens, causou alterações na dinâmica hídrica local, principalmente na lagoa Feia a qual perdeu cerca de $40 \%$ do seu espelho d'água no período de 1846 a 2010. Destaca-se, dentre as intervenções, a construção do Canal da Flecha, em 1944, que teve por objetivo criar um sistema de controle do nível da lagoa Feia. A gestão desse mecanismo acirrou os conflitos entre pescadores, agricultores e pecuaristas, em razão de suas demandas naturalmente conflitantes.

PALAVRAS-CHAVE: Baixada Campista, Obras de Drenagem, Gestão Participativa.

\section{ANTHROPIC INTERVENTIONS AT A WATERSHED AND CONFLICTS BASED ON WATER USAGE: FEIA LAGOON'S CASE.}

\begin{abstract}
Since the beginning of the local territorial occupation of the Feia Lagoon watershed, were promoted changes in the water dynamics, which was considered an obstacle to progress. Sugar cane crops were especially important for the region, since the local natural conditions were very favorable. The expansion of this activity demanded the implementation of various drainage projects to dry flooded areas, reduce the surface area of the lagoons and river beds. In this sense, this article's objective is to elaborate a bibliographic revision, identifying the main anthropic interventions in the Feia lagoon's watershed's water regime, correlating them with the conflicts that stem from the water usage. For such, research was done in both printed and digital media, including using search
\end{abstract}

engines like the Portal de Periódicos CAPES/MEC and Google Scholar. The analysis of those studies allowed to conclude that the way the Feia lagoon was occupied, justified by the constant need to expand agricultural and pasture areas, cause large scale changes in the regional water dynamics, especially at the Feia Lagoon, which lost around $40 \%$ of it's original surface area from 1846 to 2010. Out of all those anthropic interventions, it's important to highlight the construction of the Flecha Canal, in 1944, whose goal was to create a level control system for the Feia lagoon. The management of this mechanism escalated the conflicts between fishermen, farmers and cattle owners, due to their naturally conflicting demands.

KEYWORDS: Baixada Campista, Drainage Works, Participative Management. 


\section{INTRODUÇÃO}

As zonas costeiras são áreas de transição e interação entre litosfera, atmosfera, hidrosfera continental e oceânica. As alterações ou mudanças advindas da interação entre as atividades humanas e o meio físico natural são uma premissa para a definição destes espaços (Barragán, 2016).

De acordo com Prado Junior (2012), a ocupação territorial do Brasil se deu majoritariamente pelo litoral, dentre outros motivos pelas características de relevo. Nas regiões Sudeste e Sul a formação da abrupta Serra do Mar, com rebordo oriental de planalto inclinando-se para o continente, faz com que grande parte dos rios fluam em direção ao interior, dificultando a navegação e, por consequência, a ocupação da porção continental.

A Baixada Campista está compreendida às margens do rio Paraíba do Sul no trecho próximo à sua foz e abrangendo áreas dos municípios de Campos dos Goytacazes, São Francisco de Itabapoana, São João da Barra e Quissamã. De acordo com Lamego (1955) a região se formou através de processos sedimentológicos que se estenderam entre o Plioceno e o Holoceno. Sucessivos eventos de transgressão e regressão marinhas transformaram a baía de desembocadura do rio Paraíba do Sul na ampla várzea atual. A lagoa Feia resultou, portanto de uma falha nos processos deposicionais formadores da Baixada Campista.

Os primeiros a desbravarem a região foram os povos indígenas, seguidos dos colonizadores europeus. As comunidades indígenas viviam em relativa harmonia ambiental, pois não desenvolviam projetos de transformação da natureza para atender suas necessidades, apenas adaptavam-se às condições locais. Essa harmonia foi quebrada a partir da chegada dos colonizadores europeus, os quais promoveram diversas alterações na paisagem, principalmente na dinâmica hídrica local (Lamego,1974).

Ainda segundo Lamego (1974), as características de relevo e clima conferiam vocação natural para desenvolvimento de atividades agropastoris na região. Por outro lado, as vastas áreas alagadas, canais naturais, rios e lagoas, eram vistos pelos produtores rurais com empecilho ao desenvolvimento, porquanto limitavam a expansão das áreas cultivadas.

A atividade canavieira iniciou e, especialmente em períodos de valorização do açúcar no mercado internacional, se consolidou o entendimento de que a monocultura canavieira seria a melhor alternativa econômica local, determinando o uso e ocupação do solo e elevando o cultivo de cana à categoria de ocupação territorial preponderante, praticamente eliminando outras atividades produtivas. Esta configuração justificaria intervenções e obras hídricas para ampliação das áreas cultivadas que, posteriormente, deram origem aos primeiros conflitos pelo uso da água (Carneiro, 2004).

O objetivo deste trabalho é elaborar uma revisão bibliográfica a respeito da ocupação da bacia hidrográfica da lagoa Feia, identificando os principais conflitos relacionados à água, correlacionando-os com as atividades econômicas desenvolvidas e as intervenções antrópicas no regime hídrico. 


\section{O CENÁRIO ATUAL DA ÁGUA NO BRASIL}

O Brasil tem passado por inúmeros problemas relacionados à água no neste início do século $X X I$, sejam estes relacionados à qualidade ou à quantidade disponíveis. O verão dos anos 2000 para 2001 nas Regiões Nordeste e Sudeste apresentou chuvas inferiores a 50\% da média histórica. Os baixos volumes de precipitação aliados a pífios investimentos no setor de geração de energia hidroelétrica nos anos subsequentes deram causa à crise energética do início dos anos 2000, uma das maiores da história recente (Marengo \& Alves, 2005).

Em 2003 o rompimento de uma barragem no município de Cataguases-MG liberou cerca de 20 milhões de litros de rejeitos tóxicos no rio Pomba (IBAMA, 2003).

Em 2014 a cidade de São Paulo passou pela maior crise hídrica dos últimos 80 anos, o que trouxe enormes alterações na rotina da população e exigiu uma série de providências dos órgãos responsáveis pelo abastecimento (Marengo \& Alves, 2016).

Em 2015 uma barragem de rejeitos de minério de ferro localizado na cidade de Mariana-MG rompeu, contaminando o Rio Doce, causando grande devastação, mortes e degradação ambiental em todo o curso hídrico, desde o ponto de rompimento até sua foz no Estado do Espírito Santo (IBAMA, 2015).

A utilização de recursos hídricos em grandes empreendimentos no Brasil como as usinas hidrelétricas de Jirau (rio Madeira, Porto Velho/RO), Belo Monte (rio Xingu, Pará) e em outras atividades envolvendo geração de energia tem promovido muitas mudanças na esfera socioambiental dos locais afetados. O panorama atual da água no Brasil tem evidenciado a priorização do uso para esses grandes empreendimentos em detrimento das atividades das comunidades tradicionais. A apropriação dos recursos hídricos para fins privados, desapropriação de terras, degradação da qualidade e quantidade da água, eventos de estiagem ou inundações, acidentes e outros tem contribuído para a criação de um ambiente de constante degradação de recursos, fomentando os conflitos pelo uso da água (Guimarães, 2017).

Muitos dos conflitos estão relacionados à geração de energia hidroelétrica, pois esta é a principal fonte energética nacional, representando $64,5 \%$ do total produzido (ANA, 2017).

\section{CONFLITOS PELO USO DA ÁGUA}

Segundo Galvão e Bermann (2015) o sistema jurídico brasileiro preconiza que a gestão dos recursos hídricos deve promover o uso múltiplo das águas. Dessa forma todos os setores usuários devem possuir igual direito de acesso. A única exceção diz respeito a momentos de escassez, nos quais a prioridade é de abastecimento humano e dessedentação animal (Brasil, 1997).

A primeira normatização nacional voltada a regular a apropriação e uso da água foi o Decreto Federal 24.643 de 1934, o Código de Águas. A promulgação se deu numa época de modernização e desenvolvimento econômico em que se entendia a água como um recurso abundante. A partir da década de 1970, a industrialização e crescimento populacional intensos fizeram surgir situações de escassez em determinadas regiões do país contribuindo para o surgimento de conflitos pelo uso da 
água. A legislação então em vigor já não era capaz de oferecer ferramentas de gestão e coordenação dos recursos para otimizar os usos (ANA, 2017).

No final da década de 1990, finalmente houve um salto legal capaz de modernizar o gerenciamento de recursos hídricos criando ferramentas adequadas à realidade atual. A evolução histórica que culminou nesse novo patamar de regulamentação pode ser demonstrada na figura 1.

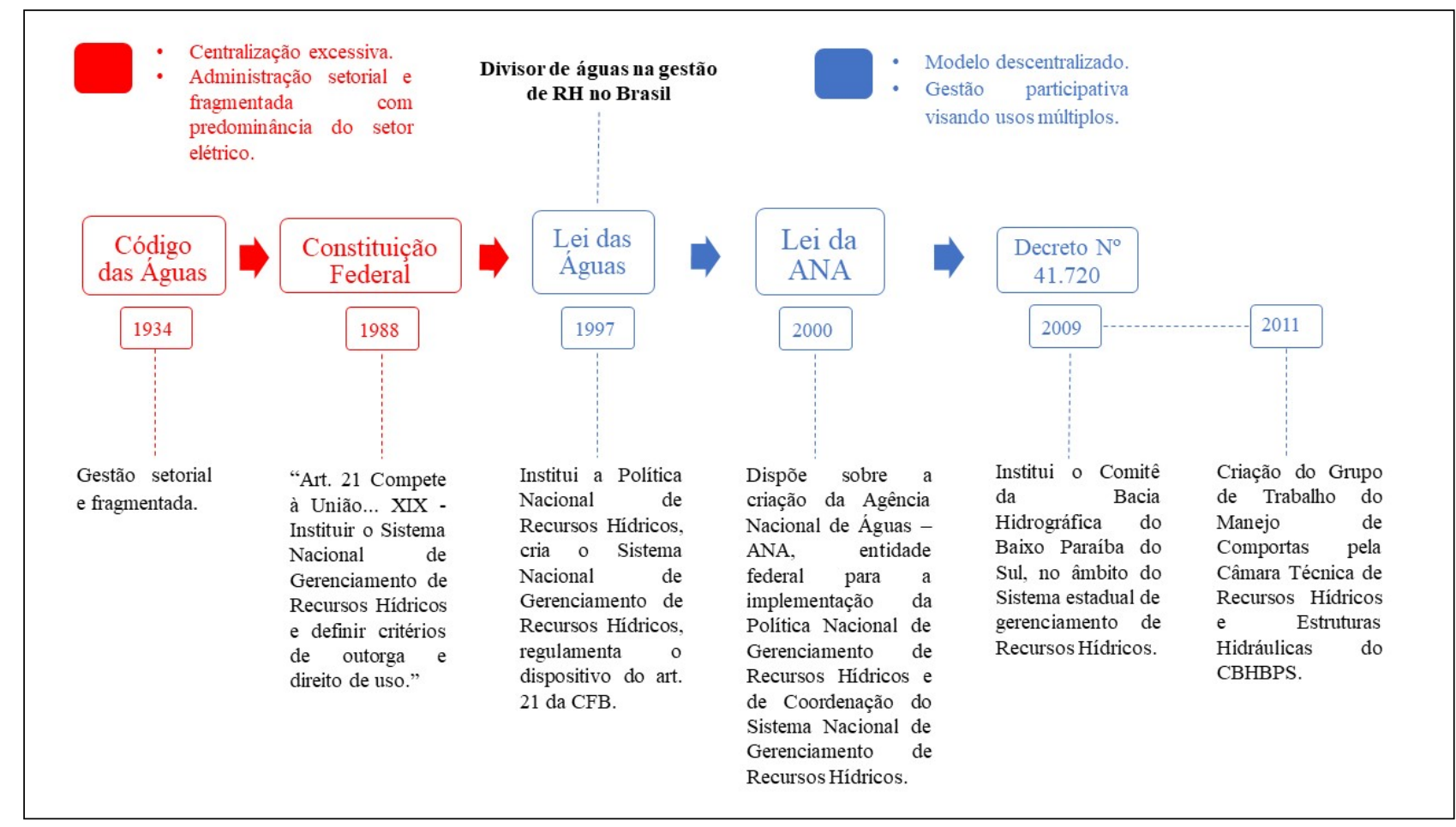

Figura 1: Evolução do sistema normativo da gestão de recursos hídricos nacional e regional. Fonte: Adaptado de ANA (2017).

A Lei das Águas representou grande avanço normativo na gestão dos recursos hídricos. Antes, o modelo legal era extremamente centralizador e a administração se mostrava fragmentada, com inclinação a atender os anseios do setor elétrico. O novo modelo teve por metas a descentralização, o fortalecimento da gestão participativa e a promoção dos usos múltiplos como ferramenta de mediação dos conflitos (ANA, 2017). Como fruto desse novo modelo de gestão surgem os Comitês de Bacia, como o Comitê de Bacia Hidrográfica do Baixo Paraíba do Sul criado em 2009 (que em 2016 incorporou a bacia do rio Itabapoana).

Mesmo com o avanço legal em relação à gestão das águas, muitos conflitos floresceram em várias regiões do país. A posição do Brasil no cenário internacional, onde ocupa uma posição de destaque quanto à disponibilidade de água doce, traz a falsa impressão de que o país não está sujeito a problemas com o uso da água. A disposição territorial do recurso considerando as escalas espacial e temporal e as mais variadas atividades econômicas e a degradação da qualidade da água tem gerado áreas de conflito (ANA, 2017).

Little (2003) alerta para o fato de que mesmo em áreas de abundância de água os conflitos podem surgir. Portanto, é necessário ampliar o foco para além do aspecto da quantidade, considerando o amplo espectro de fatores que podem corroborar para a deflagração de um conflito. 
O foco, portanto, deve estar nos usos variados, buscando-se identificar os aspectos qualitativos e quantitativos: quantidade de água a ser utilizada, quem, qual será o uso, quais os custos, quais os impactos ambientais.

As bacias hidrográficas comportam diferentes grupos sociais e para entende-los devemos considerar as adaptações ecológicas inerentes ao seu estilo de vida, seus sistemas produtivos, os recursos explorados e a contextualização social que explica as adaptações ecológicas implementadas e as reivindicações por recursos, em especial, terras e água. Na medida em que se direcionam as atenções para os grupos sociais torna-se nítido que existem usos e interesses conflitantes, o que exige abordagens que considerem os conflitos como elemento naturalmente presente nas bacias hidrográficas (Little, 2003).

A bacia hidrográfica da lagoa Feia insere-se perfeitamente neste contexto contemporâneo, pois apesar de gozar de farto estoque de águas, os conflitos têm emergido. Os diferentes grupos sociais, sejam pescadores, agricultores, pecuaristas e núcleos populacionais com suas distintas necessidades requerem usos variados da água, o que insere o caráter conflituoso nas relações. Tal conjuntura impõe a necessidade de se aperfeiçoar ou criar novas ferramentas de gestão mais eficientes na mediação das relações. Para tal, é necessário conhecer os atores sociais inseridos nesses processos, suas particularidades, necessidades relacionadas ao uso da água e a interação entre si.

Na década de 1970 a agroindústria canavieira passou por um intenso processo de modernização, por meio da injeção de recursos públicos, o que propiciou significativo aumento da capacidade produtiva instalada. Contudo, os usineiros alegavam que a baixa produtividade no campo não permitia a plena utilização da máquina produtiva, imputando a culpa na estagnação da produção agrícola. Acreditavam que os períodos de seca eram determinantes para criar momentos de ociosidade nas usinas. Tal percepção fundamentou a introdução de novas técnicas de irrigação. Os canais, até então utilizados basicamente para a drenagem da baixada campista, passam a ser utilizados na irrigação das plantações (Carneiro, 2004).

De acordo com Carneiro (2004), a partir da ampliação da irrigação na região, começam a surgir conflitos entre os usineiros e os produtores rurais. Além disso, os pescadores começam a ter sérios problemas à medida em que as áreas alagadas vão sendo drenadas para atender às demandas dos produtores rurais.

Um dos primeiros conflitos documentados ocorreu em 1978 quando cerca de seiscentas pessoas entre pescadores e moradores da localidade de Ponta Grossa dos Fidalgos paralisaram uma obra de drenagem do extinto Departamento Nacional de Obras de Saneamento - DNOS (Figura 2), que tinha por objetivo criar um canal submerso ligando os rios Ururaí e Macabu ao Canal da Flecha, rompendo um vertedouro natural existente na saída da lagoa Feia, conhecido como durinho da valeta (Valpassos, 2006). A justificativa técnica empregada era que a abertura do durinho da valeta permitiria maior eficiência no controle do nível da lagoa Feia. Já os pescadores acreditavam que o impacto seria enorme e causaria alterações fatais no regime hídrico regional. 


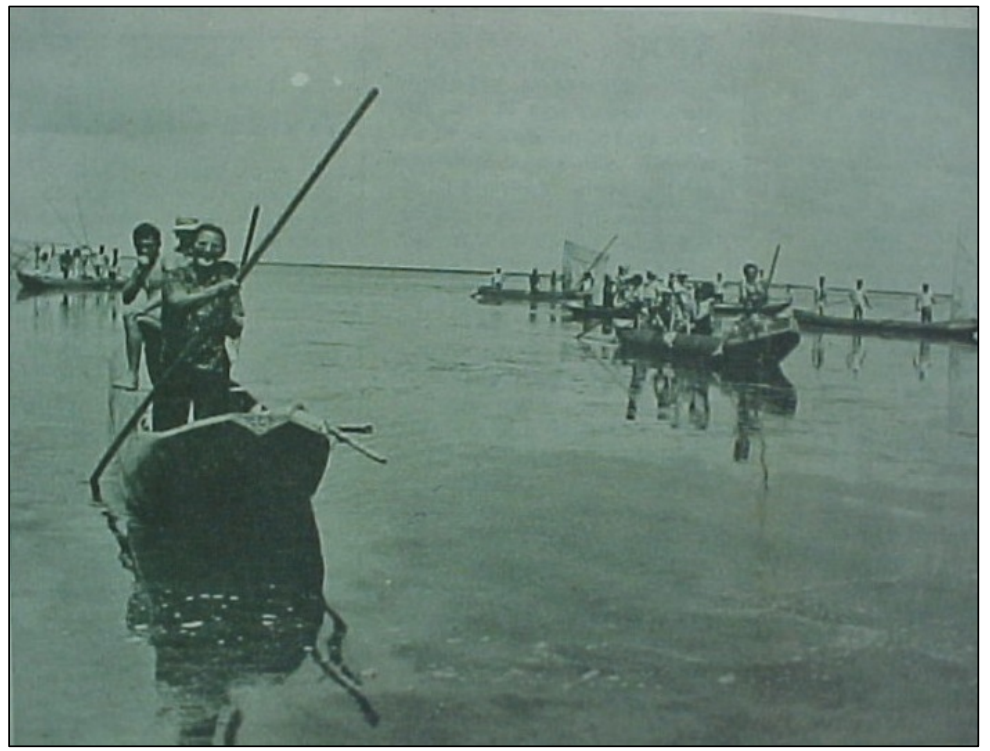

Figura 2: Comitiva se dirigindo à abertura do canal submerso. Fonte: Valpassos (2006).

Desde então, outros tantos conflitos eclodiram. Pescadores, produtores rurais e usineiros buscam atender suas demandas as quais são, em muitas ocasiões, conflitantes. De acordo com Carneiro (2004) podemos enumerar alguns dos principais incidentes ocorridos: Em 26 de outubro de 1979, pescadores do Farol de São Tomé se concentraram junto ao Canal de Quitinguta e exigiram que o DNOS reestabelecesse a ligação com o mar para a migração de peixes e camarões até as lagoas costeiras. O então Ministro do Interior, Maurício Rangel Reis, se dirigiu à localidade, fato pelo qual o corrido ficou conhecido como "buraco do Ministro". Em 13 de agosto de 1980, pescadores da lagoa do Campelo retiraram as comportas do canal do Cataia. O canal, antes ligação natural entre a lagoa do Campelo e o rio Paraíba do Sul, passou a ser controlado artificialmente, gerando revolta nos pescadores locais.

\section{CARACTERIZAÇÃO DA BACIA HIDROGRÁFICA DA LAGOA FEIA}

A Bacia Hidrográfica da lagoa Feia está localizada na Região Hidrográfica do Baixo Paraíba do Sul (RH IX). Limita-se pelas coordenadas geográficas dos paralelos de latitude sul $21^{\circ} 40^{\prime}$ e $22^{\circ} 19^{\prime}$ e os meridianos de longitude oeste $41^{\circ} 07^{\prime}$ e $42^{\circ} 18^{\prime}$ em Datum SIRGAS 2000 e, de acordo com Ramalho (2005), ocupa uma área de $1.844 \mathrm{~km}^{2}$. Toda sua extensão encontra-se inserida nos limites do estado do Rio de Janeiro, abrangendo parte das áreas dos municípios de Campos dos Goytacazes, Conceição de Macabu, Carapebus, Quissamã, Macaé, Santa Maria Madalena e Trajano de Moraes. Suas principais nascentes localizam-se nas áreas de serra a montante (Serra do Mar) tendo por seus maiores contribuintes os rios Macabu e Ururaí. Inúmeros canais de drenagem também cortam toda a parte baixa da bacia totalizando $1.400 \mathrm{~km}$ de extensão. Os divisores de água da bacia estão localizados nas divisas com os municípios de São Fidelis, Cardoso Moreira, Bom Jardim e Nova Friburgo (Lima, 2014).

A lagoa Feia (Figura 3) está inserida na baixada campista, na Região Norte Fluminense. Sua formação ocorreu através da interação de processos deposicionais aluviais e marinhos ocasionados por eventos de transgressão e regressão do oceano atlântico conjugados à dinâmica de 
sedimentação do Rio Paraíba do Sul. Portanto, a lagoa Feia surgiu de uma falha neste processo de deposição.

\section{Localização da Bacia Hidrográfica da Lagoa Feia}

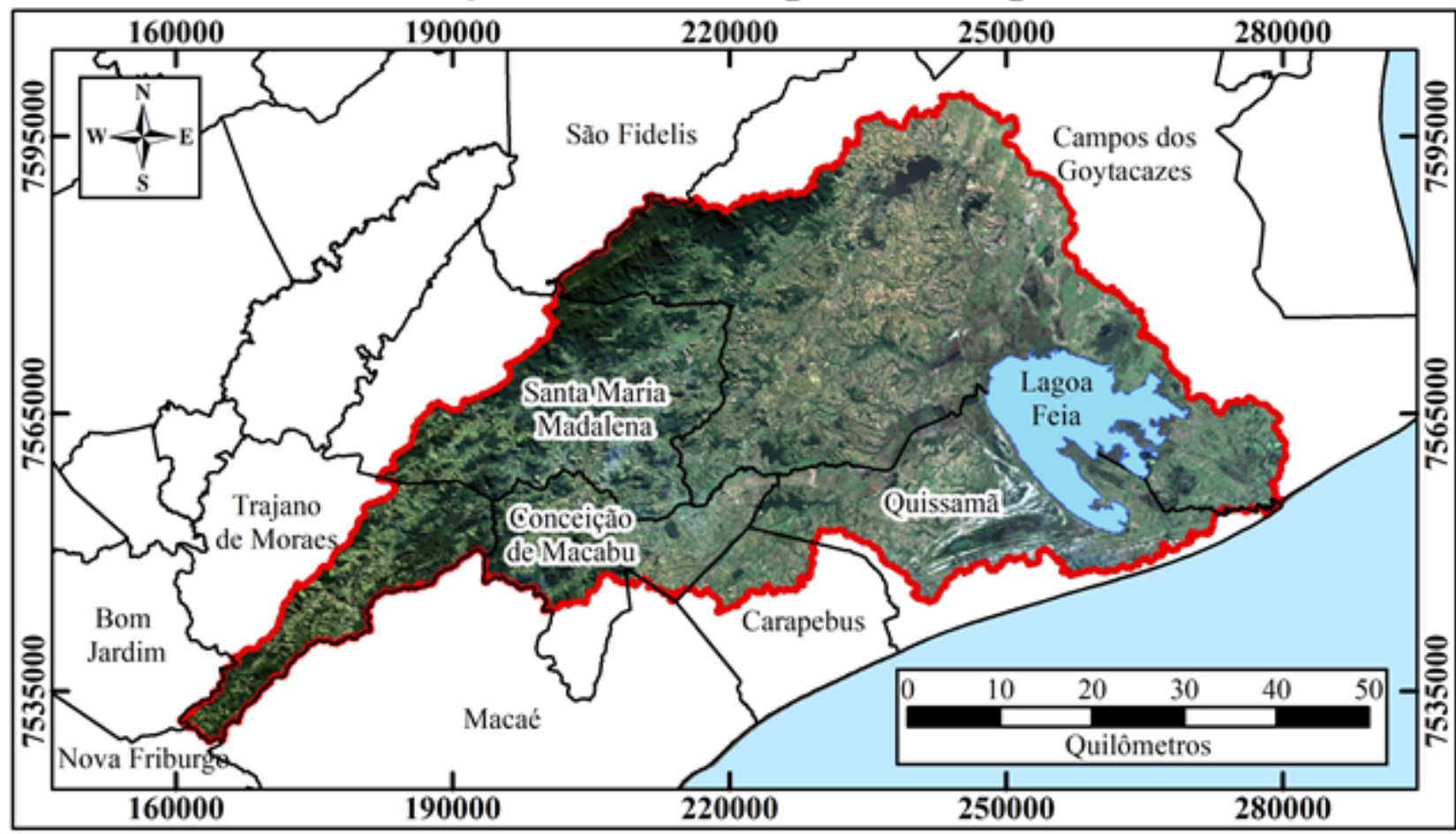

\section{Legenda}

$\sim 3$ Lagoa Feia

3 Bacia da Lagoa Feia

Limites Municipais

Região Hidrgráfica IX
Dados gerais

Datum: SIRGAS 2000

Projeção: UTM

Fuso: 24; Zona: K

Escala: $1: 1.000 .000$

\section{Fontes}

IBGE (2017); INEA (2018); USGS/LANDSAT (2018)

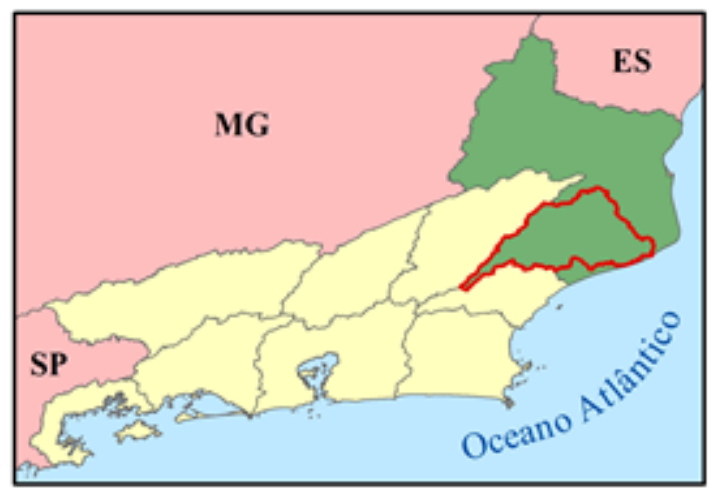

Figura 3: Localização da lagoa Feia. Fonte: Autores (2018).

\section{INTERVENÇÕES ANTRÓPICAS NA BACIA HIDROGRÁFICA DA LAGOA FEIA}

De acordo com Lamego (1974) a Baixada Campista foi colonizada pelos ameríndios desde a pré-história. As tribos indígenas locais, predominantemente, a tribo Goitacá, se instalaram às margens das lagoas e do Rio Paraíba do Sul, seguindo a fauna que acompanhava as mudanças na planície fluviomarinha. Desenvolviam apenas agricultura rudimentar tamanha a disponibilidade de alimentos. As lagoas e brejos ofereciam não só o alimento, mas proteção contra tribos invasoras. A relação entre população indígena relativamente pequena e ampla áreas e vastos recursos faziam com que suas atividades de subsistência estivessem em equilíbrio ecológico. As principais atividades eram a caça e a pesca de subsistência. A princípio se estabeleceram nas áreas mais altas da planície 
onde estavam mais protegidos das cheias. A abundância de recursos e abrigo oferecido pelas águas os fez embrenharem-se cada vez mais nas baixadas alagadas, como reporta Lamego:

E com tais agrupamentos sobre as águas nasce-Ihe a noção de segurança. Com a maior confiança própria, arrebata-se-lhe a audácia guerreira já aguçada pela inata belacidade. Animados pela invulnerabilidade do reduto inatacável, tomam-se de maior atrevimento nas emprêsas predatórias. Exercita-se-lhes o raciocínio com ardis novos defensivos.

Esta convivência, relativamente harmônica, entre o homem e os recursos naturais locais perdurou até à chegada dos colonizadores europeus, quando novas atividades foram introduzidas, iniciando-se pela criação de gado (Lamego, 1974).

A primeira tentativa da Coroa Portuguesa de efetivamente colonizar a região se deu em 1534 quando a Capitania de São Tomé foi doada a Pero Góis. A Capitania Compreendia a área que se iniciava 30 léguas além de Cabo Frio até Baixo dos Pargos na divisa com a Capitania do Espírito Santo, até 10 léguas mar adentro, totalizando 30 léguas de terra (Bidegain et al., 2002).

Ainda de acordo com Bidegain et al. (2002), a escassez de recursos financeiros aliada à forte resistência dos nativos impediu que este primeiro intento lograsse êxito e em 1546 Pero Góis devolveu as terras à Coroa. Posteriormente seu filho, Gil de Góis tentou recomeçar a colonização da região ao passo que também não foi exitoso, renunciando a posse em 1619. Em 1627 uma terceira tentativa de colonização foi iniciada por sete fidalgos, os requereram a região por sesmaria a qual se estendia da foz do rio Macaé até o rio Iguaçu (correspondente à lagoa do Açu, atualmente). Durante a ocupação, a extensão ocupada foi ampliada do Rio Macaé (Rio dos Bagres) até o rio Itabapoana (Rio Managé). As terras foram divididas em áreas aproximadamente iguais em faixas paralelas até a Serra do Mar.

De acordo com Lamego (1974) os colonos muito rapidamente perceberam o potencial local para a criação de gado, configurando esta a primeira atividade de caráter econômico local. A medida que a pecuária se ampliava crescia a percepção que as áreas alagadas impediam um pleno aproveitamento do potencial produtivo. O viés de ocupação em equilíbrio com a vida selvagem, até então desenvolvida pelas comunidades indígenas, aos poucos, foi desaparecendo.

Em 1688 se deu a primeira grande intervenção antrópica na dinâmica hídrica na bacia da lagoa Feia. Com a intenção de agilizar o escoamento das águas acumuladas na planície no período de chuva, o Capitão José de Barcelos Machado abriu a Vala do Furado. Neste local futuramente seria construído o Canal da Flecha (Soffiati, 2014).

Bidegain et al. (2002) pontua que a partir do século XVIII, a planície de aluvião passou a ser utilizada integralmente por plantações e pastagens. A restinga e os tabuleiros começaram a ser explorados e ocupados e a vegetação foi gradualmente removida. Devido às características topográficas, as áreas de serra ainda permaneciam intocadas. Nesse período, os proprietários de terra faziam a limpeza manual dos canais naturais e rios utilizados para garantir a navegação.

A produção agrícola da região, em sua maioria, era escoada através do porto de São João da Barra, o qual apresentava condições inadequadas pela foz considerada perigosa às embarcações. Como alternativa foi concebido o projeto de Canal Campos/Macaé. A intenção era ligar a região de Campos ao porto de Macaé por uma via de transporte fluvial. O projeto foi iniciado em 1844 e 
finalizado em1861. Obra considerada de grande porte para a época, interligou as bacias do rio Paraíba do Sul, lagoa Feia e rio Macaé, perfazendo 96 quilômetros de extensão, largura média de 11 metros e profundidade média de 1,30 metros (Bidegain et al., 2002).

A partir do final do século XIX, ocorreu acelerada modernização da agroindústria canavieira em toda a região Norte Fluminense. Esse processo culminou na centralização da produção em grandes engenhos centrais os quais substituíram os rudimentares engenhos de pequenos produtores. À medida em que a produtividade aumentava, crescia, também, a pressão para a ampliação das plantações sobre as áreas alagadas, as quais deveriam ser drenadas para tal. Visando subsidiar tecnicamente as possíveis medidas a serem implementadas, vários estudos foram concebidos a partir de então. Várias comissões de saneamento foram criadas (Quadro 1), em níveis federal e estadual. Muitos dos trabalhos dessas comissões se perderam até que em 1934, Hidelbrando de Araújo Góes, então Chefe da Comissão de Saneamento da Baixada Fluminense, reuniu e sistematizou todo o material produzido anteriormente (Bidegain et al., 2002).

Quadro 1: Comissões e Entidades responsáveis por estudos e obras hidráulicas a partir de 1894.

\begin{tabular}{|c|c|c|c|}
\hline ENTIDADE & SUBORDINAÇÃO & ANOS & $\begin{array}{l}\text { ENGENHEIRO } \\
\text { RESPONSÁVEL }\end{array}$ \\
\hline $\begin{array}{l}\text { Comissão de Estudos e } \\
\text { Saneamento da Baixada do } \\
\text { Estado do Rio de Janeiro }\end{array}$ & Governo Fluminense & $1894-1901$ & $\begin{array}{l}\text { João Teixeira Soares e } \\
\text { Marcelino Ramos da } \\
\text { Silva }\end{array}$ \\
\hline $\begin{array}{l}\text { Comissão do Porto de São João } \\
\text { da Barra e Baixada do Nordeste } \\
\text { do Estado do Rio de Janeiro }\end{array}$ & $\begin{array}{l}\text { Inspetoria Federal } \\
\text { de Portos, Costas e } \\
\text { Vias Navegáveis }\end{array}$ & 1912 & $\begin{array}{l}\text { José Antônio Martins } \\
\text { Romeu }\end{array}$ \\
\hline $\begin{array}{l}\text { Comissão do canal de Macaé a } \\
\text { Campos }\end{array}$ & $\begin{array}{l}\text { Inspetoria Federal } \\
\text { de Portos, Costas e } \\
\text { Rios Navegáveis }\end{array}$ & $1918-1925$ & $\begin{array}{l}\text { Lucas Bicalho, cândido } \\
\text { Borges e J.B. Moraes } \\
\text { Rego }\end{array}$ \\
\hline $\begin{array}{l}\text { Comissão de Estudos e Obras } \\
\text { contra as inundações da lagoa } \\
\text { Feia e Campos de Santa Cruz }\end{array}$ & $\begin{array}{l}\text { Inspetoria Federal } \\
\text { de Portos, Costas e } \\
\text { Rios Navegáveis }\end{array}$ & $1925-1928$ & Lucas Bicalho \\
\hline Escritório Saturnino de Brito & $\begin{array}{c}\text { Governo Fluminense } \\
\text { Diretoria de Obras } \\
\text { Pública }\end{array}$ & $1925-1930$ & $\begin{array}{l}\text { Francisco Saturnino } \\
\text { Rodrigues de Brito }\end{array}$ \\
\hline $\begin{array}{l}\text { Comissão de Saneamento da } \\
\text { Baixada Fluminense }\end{array}$ & Governo Federal & $1933-1940$ & $\begin{array}{l}\text { Alfredo Conrado de } \\
\text { Niemeyer e Hildebrando } \\
\text { de Araújo Góes }\end{array}$ \\
\hline $\begin{array}{l}\text { Departamento Nacional de } \\
\text { Obras de Saneamento - DNOS }\end{array}$ & Governo Federal & $1940-1989$ & ----------------------------- \\
\hline
\end{tabular}

Fonte: Adaptado de Bidegain et al. (2002)

Com base nos estudos e revisões realizados, a Comissão de Saneamento da Baixada Campista deu início a diversas obras. Na tabela 1 pode-se verificar detalhadamente as intervenções realizadas. 
Tabela 1: Obras realizadas pela Comissão de Saneamento da Baixada Campista.

\begin{tabular}{lcc}
\multicolumn{1}{c}{ OBRA } & UNIDADE & QUANTIDADE \\
\hline Limpeza de cursos d'água & $\mathrm{km}$ & 800,0 \\
Conservação de cursos d'água & $\mathrm{km}$ & 865,0 \\
Construção manual de cursos d'água & $\mathrm{km}$ & 320,0 \\
\hline Dragagem de canais & $\mathrm{km}$ & 19,0 \\
Construção de dique de alvenaria & $\mathrm{km}$ & 15,5 \\
Construção de dique de terra & $\mathrm{km}$ & $\mathbf{7 , 6}$ \\
Total & & $\mathbf{2 . 0 2 7 , 1}$ \\
Construção de dique de alvenaria & $\mathrm{m}^{2}$ & $33.890,0$ \\
Construção de dique de terra & $\mathrm{m}^{2}$ & $\mathbf{1 5 0 . 0 0 0 , 0}$ \\
Dragagem de canais & $\mathrm{m}^{\mathbf{2}}$ & $626.510,0$ \\
\hline Total & & $\mathbf{8 1 0 . 4 0 0 , 0}$ \\
\hline
\end{tabular}

Fonte: Adaptado de Lamego (1974).

Em 1940 é criado o DNOS - Departamento Nacional de Obras de Saneamento. Tendo como missão institucional aplicar a política nacional de saneamento geral e básico, o órgão deu continuidade às obras de drenagem em toda a baixada campista. De acordo com Valpassos (2006), a maior a obra realizada pelo DNOS foi a abertura do Canal da Flecha. Com 13 quilômetros de extensão e 120 metros de largura, tinha por finalidade substituir os sistemas naturais de drenagem da lagoa Feia, compostos por vários rios e canais.

As inúmeras alterações realizadas na bacia hidrográfica contribuíram de maneira decisiva para a redução das dimensões da lagoa Feia, especialmente aquela promovidas pelo DNOS (Lima, 2014). Na tabela 2 pode-se verificar a redução do espelho d'água.

Tabela 2: Série histórica do espelho d'água da lagoa Feia.

\begin{tabular}{ccc} 
Ano & Área $\left(\mathbf{k m}^{\mathbf{2}}\right)$ & Perímetro $(\mathbf{k m})$ \\
\hline 1846 & 336 & 151 \\
1939 & 290 & 123 \\
2006 & 172 & 103 \\
2010 & 200 & 110 \\
\hline
\end{tabular}

Fonte: Adaptado de Lima (2014).

Portanto, em termos percentuais representou redução da ordem de 40\% no período de 1846 a 2010, ou seja, uma diminuição de 136 quilômetros quadrados.

Um dos corpos hídricos afetados pela obra do Canal da Flecha foi a lagoa da Ribeira. Esta, que apresentava ligação natural com a lagoa Feia, sendo praticamente uma extensão da mesma, sofreu forte redução em sua área (Soffiati, 2009).

A lagoa da Ribeira está localizada no município de Quissamã, a aproximadamente 500 metros da Sede municipal, a 08 quilômetros do mar e a 13 quilômetros da lagoa Feia (Figura 4). A comunicação entre as duas lagoas se dá por meio de um canal e o ponto em que se ligam é conhecido como Pontal (Figura 5). 


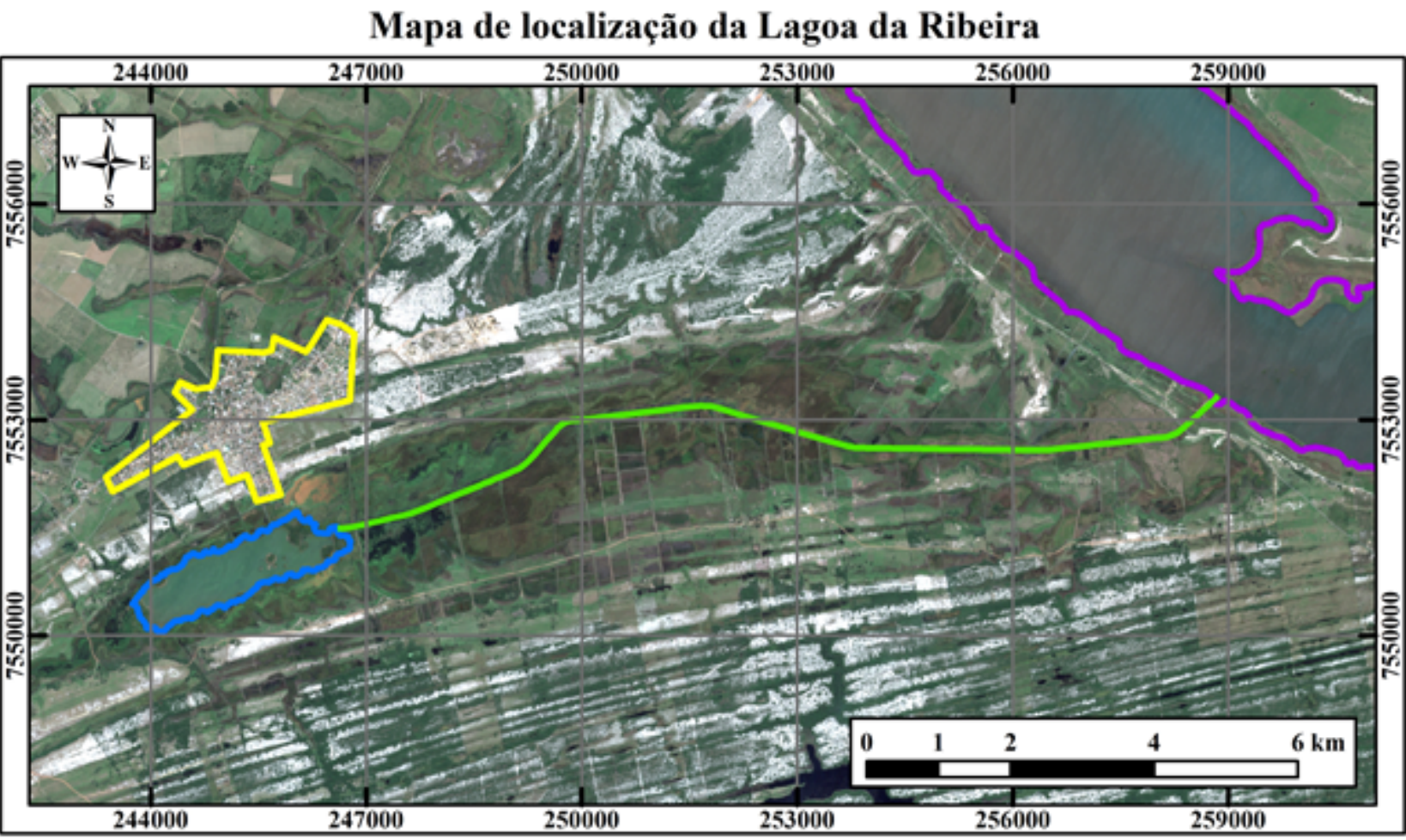

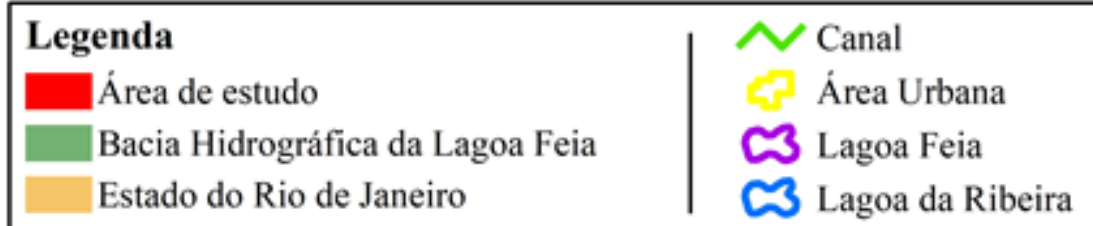

\section{Informações cartográficas:}

Datum: Sirgas 2000; Projeção: UTM; Fuso: 24; Zona: K; 1:125.000

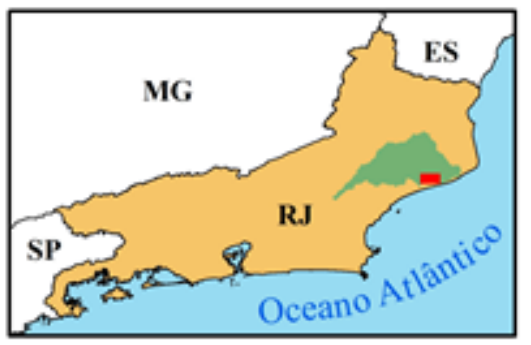

Figura 4: Localização da lagoa da Ribeira. Fonte: Autores (2018).

De acordo com Bidegain et al. (2002), a lagoa da Ribeira naturalmente se ligava com a lagoa Feia e possui, atualmente, espelho d'água de aproximadamente 2 quilômetros quadrados. Considerando-se a área permanentemente alagada ocupa por volta de 5 quilômetros quadrados. A região é cercada por planícies inundáveis, charcos e restinga que atingem por volta de 30 quilômetros quadrados em períodos de chuva (Tavares \& Siciliano, 2013). 


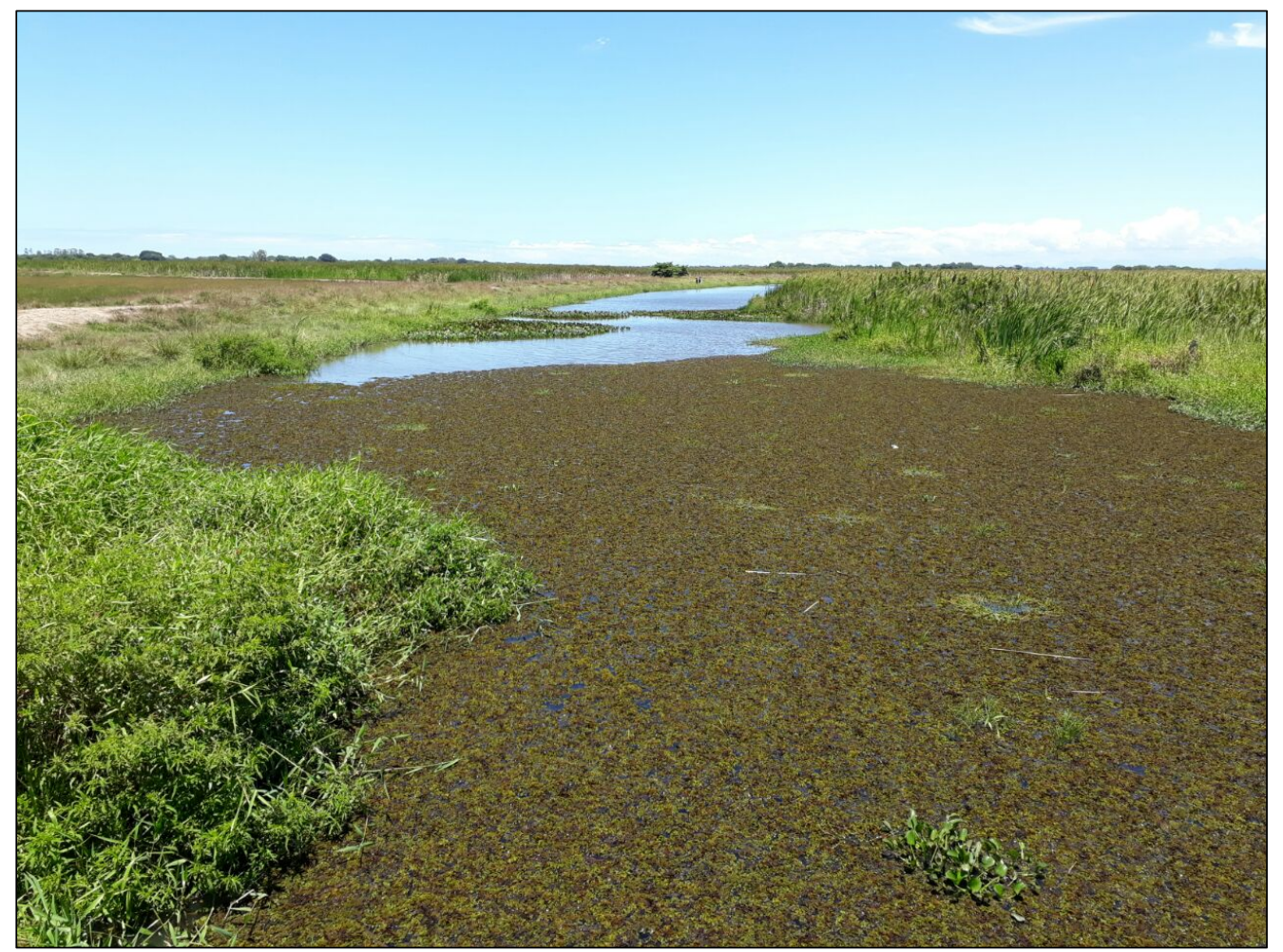

Figura 5: Pontal - local onde o canal da Ribeira se conecta à lagoa Feia. Fonte: Arquivo pessoal.

No ano de 2006 foi criada a unidade de conservação denominada Área de Proteção Ambiental da Lagoa da Ribeira. A APA abrange uma área de 3.038,57 hectares e, apesar de estar legalmente constituída, encontra-se em processo de implementação.

A lagoa, suas planícies inundáveis periféricas e a vegetação de restinga constituem um ecossistema de elevada importância socioeconômica e ambiental. Tavares e Siciliano (2013) reportam que a região da lagoa Feia, incluindo a Ribeira, possui grande variedade de aves aquáticas.

De acordo com representantes da Colônia de Pesca local (Z27), dos seus 140 pescadores registrados, cerca de 70 pescadores vivem do pescado da lagoa da Ribeira. Entre as principais variedades pescadas estão traíra, bagre, piau, robalo, tainha, corvina, acará e curimatã.

Inúmeros produtores rurais estão estabelecidos na APA da Ribeira e exercem atividades de agricultura e pecuária.

Tanto, produtores rurais, como pescadores tem relatado degradação das condições hídricas locais. Muitos poços utilizados para abastecimento estão abandonados devido ao aumento na salinidade e/ou rebaixamento de nível do lençol freático, fato que tem levado a Prefeitura Municipal a distribuir água tratada em caminhões pipa. Os pescadores alegam que tem havido constante redução de variedades e quantidade de peixes. Essas alterações têm sido atribuídas às manobras das comportas do Canal da Flecha. Como a lagoa da Ribeira apresenta cota mais elevada que a lagoa Feia, quando as comportas são abertas, a partir de determinado nível (carece de estudo técnico para definição) a Ribeira sofre perda considerável de seus nível e área, situação que perdura grande parte do ano e é agravada em ciclos mais longos de seca. 
Outra questão que merece destaque é a relação entre atividades antrópicas e processos de eutrofização da lagoa Feia e seus tributários. A eutrofização está relacionada à fertilidade de um ambiente aquático e, notadamente, decorre da alta disponibilidade de nitrogênio e fósforo aos organismos. Pode ocorrer naturalmente ou pela ação humana e resulta no crescimento excessivo de organismos aquáticos autotróficos como algas, cianobactérias e macrófitas aquáticas (Araújo et al., 2013). Neste sentido, Silva (2018) observa que a lagoa Feia apresenta estado trófico elevado, variando a intensidade entre períodos de secas e chuvosos. No verão, os deflúvios mais intensos requerem frequentes manobras de abertura das comportas do Canal da Flecha o que representa movimentação da coluna d'água e contribui para o revolvimento de nutrientes depostos no fundo do corpo hídrico. Além disso, nos meses de outubro a dezembro ocorre aumento na velocidade do vento e o processo se intensifica. Ainda segundo Silva (2018), a ocupação do solo na bacia hidrográfica, marcada pela forte presença do cultivo de cana-de-açúcar e pecuária, contribui para este quadro com o aporte de nutrientes.

\section{QUADRO ATUAL DA GESTÃO DO NÍVEL DA LAGOA FEIA}

Atualmente, a operação das comportas do Canal da Flecha está a cargo do INEA - Instituto Estadual do Ambiente. No entanto, a gestão e as tomadas de decisão quanto a determinação dos níveis de abertura e fechamento das comportas cabe ao Comitê de Bacia Hidrográfica do Baixo Paraíba do Sul e Itabapoana - CBHBPSI, organismo colegiado pertencente ao Sistema Nacional de Gerenciamento de Recursos Hídricos - SNGRH responsável pela gestão descentralizada na Região Hidrográfica IX, RH - IX, do Estado do Rio de Janeiro. O CBHBPSI foi criado em 2009, por meio do Decreto Estadual no 41.720. Desde então o colegiado vem aprimorando a gestão do sistema de controle de nível assim como arbitrando conflitos.

Entre as medidas adotadas para o desenvolvimento de metodologias e ferramentas de gestão destaca-se a criação das Câmaras Técnicas, sendo elas: Câmara Técnica de Recursos Hídricos e Estruturas Hidráulicas, Câmara Técnica para Assuntos Legais e Institucionais, Câmara Técnica de Defesa Civil e Câmara Técnica da Pesca. A gestão do nível da lagoa Feia, instrumentalizada pelas comportas do Canal da Flecha, é acompanhado pela Câmara Técnica de Recursos Hídricos e Estruturas Hidráulicas, a qual instituiu o Grupo de Trabalho de Manejo das Comportas. Este é composto por 12 integrantes. A metodologia utilizada para as tomadas de decisão consiste na comunicação entre os componentes por correio eletrônico (e-mail). Quando um integrante solicita, mediante fundamentação técnica, a abertura ou fechamento das comportas, os demais se posicionam e a deliberação se dá pela decisão da maioria que é comunicada ao INEA para que possa ser posta em prática.

A definição do nível tem sido constante objeto de discussão no CBHBPSI. Dada a importância regional da lagoa Feia sob os aspectos ambiental, socioeconômico, como manancial das populações vizinhas, o gerenciamento tem se mostrado um grande desafio para o órgão gestor. A busca por aprimoramento gerencial tem apresentado bons resultados, entretanto a carência de trabalhos técnico-científicos que possam subsidiar a implementação de metodologias capazes de diminuir o grau de empirismo na tomada de decisão tem sido um fator limitante. 


\section{CONCLUSÃO}

A bacia hidrográfica da lagoa Feia sofreu, em pouco mais de 500 anos da chegada dos colonizadores europeus, uma série de transformações. De uma região de vastas áreas alagadas povoadas por populações que viviam em relativa harmonia, passou por fases de extremas mudanças relacionadas à introdução de cultura canavieira e da pecuária.

A intenção de transformar as condições locais adaptando-as às necessidades econômicas da sociedade causou brutais transformações nas condições hídricas, alterando de forma definitiva toda a dinâmica pluvial local. As obras de drenagem para ampliação das áreas para atividades agrícolas fizeram reduzir o espelho d'água da lagoa Feia de maneira dramática.

Se, por um lado, as intervenções humanas atenderam ao propósito para o qual foram idealizadas (reduzir as áreas de alagamentos, ampliar as áreas de cultivo e pecuária, permitindo, de modo geral, o domínio da dinâmica hídrica regional), as mudanças promovidas atendiam a um determinado grupo social em detrimento de outro(s), tornando os conflitos pelo uso da água inevitáveis. A drenagem das áreas alagadas para cultivo de cana-de-açúcar e criação de gado trouxe inúmeros problemas para as comunidades pesqueiras, por exemplo.

Se os grupos economicamente mais poderosos não forem freados, a lagoa Feia e as áreas alagadas em seu entorno podem vir a sofrer dessecamento sem precedentes. Seria a construção de um verdadeiro desastre ambiental e o fim das comunidades de pescadores.

Por isso, é necessário se reavaliar a forma como se está sendo ocupada a bacia hidrográfica da lagoa Feia e as atividades econômicas desenvolvidas, para que os grupos sociais não incorram nos erros pretéritos os quais acarretam mudanças negativas na dinâmica hídrica local. É preciso buscar o fortalecimento dos mecanismos de gestão descentralizada, com vistas a promover o uso múltiplo da água. O investimento em pesquisas científicas deve ser prioridade, uma vez que o aprimoramento da gestão depende de um arcabouço técnico disponível. Reconhecer o caráter multidimensional das relações sociais das populações de uma bacia hidrográfica, entendendo que cada grupo possui suas especificidades e necessidades é de importância fundamental para se evitarem os conflitos pelo uso da água e promover a conservação deste recurso fundamental ao homem e à vida.

\section{REFERÊNCIAS BIBLIOGRÁFICAS}

ANA (2017). Agência Nacional de Águas. Conjuntura dos Recursos Hídricos no Brasil. Disponível em: http://www3.ana.gov.br/portal/ANA/@@search?Subject\%3Alist=conjuntura\%20dos\%20recur sos\%20h\%C3\%ADdricos\%20no\%20brasil. Acesso em: 22 abr. 2018.

Araújo, J. A. F., Sales, R. J. M., \& Souza, R. O. (2013). Risco de eutrofização em reservatórios de regiões semiáridas com uso da teoria dos conjuntos difusos. Revista de Gestão de Água da América Latina, 10(1), 29-39.

Barragán, J. M. (2016). Política, gestão e litoral: uma nova visão da Gestão Integrada de Áreas Litorais. Madrid: Tébar Flores. 
Bidegain, P., Bizerril C., \& Soffiati, A. (2002). Lagoas do Norte Fluminense - (Perfil Ambiental: Cooperação Técnica Brasil - Alemanha, Projeto Planágua Semads / GTZ). Rio de Janeiro.

Brasil (1997). Lei n. 9.433, de 08 de janeiro de 1997 - Institui a Política Nacional de Recursos Hídricos, cria o Sistema Nacional de Gerenciamento de Recursos Hídricos, regulamenta o Inciso Xix do Art. 21 da Constituição Federal, e altera o Art. 10 da Lei № 8.001, de 13 de março de 1990, que modificou a Lei № 7.990, de 28 de Dezembro de 1989. Brasília, DF.

Carneiro, P. R. F. (2004). Água e conflito na Baixada dos Goytacazes. Rega - Revista de Gestão de Água da América Latina, 1(2), 87-100.

Galvão, J., \& Bermann, C. (2015). Crise hídrica e energia: conflitos no uso múltiplo das águas. Instituto de Energia e Ambiente, 29(84), 43-68.

Guimaraes, R. M. A. B. (2017). Impactos socioambientais e insegurança hídrica: o caso do Complexo Logístico, Industrial e Portuário do Açu (CLIPA), no estado do Rio de Janeiro. Brasiliana - Journal For Brazilian Studies, 5(2), 201-224.

IBAMA (2015). Instituto Brasileiro do Meio Ambiente e dos Recursos Naturais. Laudo Técnico Preliminar: Impactos ambientais decorrentes do desastre envolvendo o rompimento da barragem de Fundão, em Mariana, Minas Gerais. Disponível em: http://www.ibama.gov.br/phocadownload/barragemdefundao/laudos/laudo_tecnico_prelimi nar_Ibama.pdf. Acesso em: 19 abr. 2018.

IBAMA (2003). Instituto Brasileiro do Meio Ambiente e dos Recursos Naturais. MMA atua com estados para reduzir danos de acidente ambiental em MG. Disponível em: http://www.mma.gov.br/informma/item/1186-mma-atua-com-estados-para-reduzir-danosde-acidente-ambiental-em-mg. Acesso em: 22 abr. 2018.

Lamego, A. R. (1955). Geologia das quadrículas de Campos, São Tomé, lagoa Feia e Xexé. Rio de Janeiro: DNPM.

Lamego, A. R. (1974). O Homem e o Brejo. 2a ed. Rio de Janeiro: Lidador.

Lima, V. S. (2014). Variação espaço-temporal do espelho d'água da lagoa feia, RJ. Dissertação de Mestrado, Universidade Federal do Espírito Santo, Vitória, ES, Brasil.

Little, P. E. (2203). Abundance is not enough: water-related conflicts in the amazon river basin. Disponível em: http://www.dan.unb.br/images/doc/Serie337empdf.pdf. Acesso em: 22 abr. 2018.

Marengo, J. A. \& Alves, L. M. (2005). Tendências hidrológicas da bacia do rio Paraíba do Sul. Revista Brasileira de Meteorologia, 20(2), 215-226.

Marengo, J. A. \& Alves, L. M. (2014). Crise hídrica em São Paulo em 2014: seca e desmatamento. Espaço e Tempo (Online), 19(3), 485-494.

Prado Junior, C. (2012). História Econômica de Brasil. 43 ed. São Paulo: Editora e Livraria Brasiliense. 
Ramalho, R. S. (2005). Diagnóstico do Meio Físico como Contribuição ao Planejamento do Uso da Terra do Município de Campos dos Goytacazes. Tese de Doutorado, Universidade Estadual do Norte Fluminense Darcy Ribeiro, Campos dos Goytacazes, RJ, Brasil.

Silva, L. B. C. (2018). Lagoa Feia: mudanças do uso da terra em sua bacia hidrográfica e implicações sobre sua hidroquímica e estado trófico. Tese de Doutorado, Universidade Federal do Rio de Janeiro, Macaé, RJ, Brasil.

Soffiati, A. (2014). A história da lagoa Feia através da cartografia. In: IV Seminário Regional Sobre Gestão de Recursos Hídricos. Fórum do Observatório Ambiental Alberto Ribeiro Lamego, Campos dos Goytacazes, RJ, Brasil, 5.

Soffiati, A. (2015). Chuvas e estiagens na ecorregião de São Tomé: o caso da Baixada dos Goytacazes. Historia Caribe, 10(26), 135-173.

Soffiati, A. (2009). Redução do impacto das cheias pelo manejo das águas na planície fluviomarinha do Norte Fluminense. Revista do PPGPS, 2(3), 01-33.

Tavares, D. C. \& Siciliano, S. (2013). Variação temporal na abundância de espécies de aves aquáticas em uma lagoa costeira do Norte Fluminense do estado do Rio de Janeiro, sudeste do Brasil. Biotemas, 27(1), 121-132.

Valpassos, C. A. M. (2006). Quando a lagoa vira pasto. Um estudo sobre os conflitos em torno das diferentes formas de apropriação e concepção dos espaços marginais da lagoa Feia RJ. Dissertação de Mestrado, Niterói, RJ, Brasil. 